\title{
Rhodamine B Adsorption- Kinetic, Mechanistic and Thermodynamic Studies
}

\author{
S. RAMUTHAI, V. NANDHAKUMAR ${ }^{\S}$, M. THIRUCHELVI", \\ S ARIVOLI $^{\# *}$ and V.VIJAYAKUMARAN ${ }^{\#}$
}

\author{
Department of Chemistry, \\ Seethalakshmi Achi College for Women, Pallathur - 630 107, India. \\ ${ }^{\S}$ Department of Chemistry, A.V.V.M. Sri Pushpam College, Poondi-613 503, India. \\ \#Department of Chemistry, \\ H H the Rajah's Government College, Pudukkottai-622 001, India. \\ arivu3636@yahoo.com
}

Received 20 May 2009; Revised 5 August 2009; Accepted 20 August 2009

\begin{abstract}
Adsorption of rhodamine B from aqueous solution on the surface of Moringa oliefera bark carbon was accomplished under the optimize conditions of temperature, concentration, $\mathrm{pH}$, contact time and quantity of adsorbent. Spectrometric technique was used for the measurements of concentration of dye before and after adsorption. The percentage removal of rhodamine B was calculated. The values of \% adsorption data for Moringa oliefera bark carbon system show better adsorption capacity. The experimental data are fitted to the Langmuir and Freundlich isotherm equations. The values of their corresponding constant were determined from the slope and intercepts of their respective plots. Thermodynamic parameters like $\Delta \mathrm{G}^{0}, \Delta \mathrm{H}^{0}$ and $\Delta \mathrm{S}^{0}$ were calculated. Rhodamine B-Moringa oliefera bark carbon system shows spontaneous and endothermic behaviour. The results of these investigations suggested that natural adsorbents can be utilized as adsorbent materials, because of their selectivity's for the removal of dyes.
\end{abstract}

Keywords:Activated carbon, Rhodamine B (RDB), Adsorption isotherm, Equilibrium, Kinetic and Thermodynamic parameters, Intraparticle diffusion.

\section{Introduction}

Industrial wastewater presents a challenge to conventional physico chemical and biological treatment methods. Considering both volumes discharged and effluent composition, the wastewater generated by the textile industry is rated as the most polluting among all industrial sectors. 
Wastewaters from dyeing industries released in to nearby land or rivers without any treatment because the conventional treatment methods are not cost effective in the Indian context. Adsorption is one of the most effective methods and activated carbon is the preferred adsorbent widely employed to treat wastewater containing different classes of dyes, recognizing the economic drawback of commercial activated carbon ${ }^{1,2}$.

Many investigators have studied the feasibility of using inexpensive alternative materials like pearl millet husk, date pits, saw dust buffing dust of leather industry, coir pith, crude oil residue tropical grass, olive stone and almond shells, pine bark, wool waste, coconut shell etc., as carbonaceous precursors for the removal of dyes from water and wastewater ${ }^{1-3}$.

The present study undertaken to evaluate the efficiency of a carbon adsorbent prepared from acid activated Moringa oliefera bark for the removal of dye in aqueous solution. In order to design adsorption treatment systems, knowledge of kinetic and mass transfer processes is essential. In this paper, the applicability of kinetic and mass-transfer models for the adsorption of rhodamine B onto acid activated carbon is reported.

\section{Experimental}

Carbon was prepared by treating air-dried Moringa oliefera bark carbon with con sulphuric acid in a weight ratio of 1:1. The resulting black product was kept in an air-oven maintained at $500{ }^{\circ} \mathrm{C}$ for 12 hours followed by washing with water until free of excess acid and dried at $150 \pm 5^{\circ} \mathrm{C}$. The carbon product obtained from Moringa oliefera bark carbon was ground well to fine powder and the physical properties are analyzed by usual standard methodologies.

All chemicals supplied by S.d. fine chemicals with high purity. The adsorption experiments were carried out by agitating the carbon with $10,20,30,40,50$ and $60 \mathrm{mg} / \mathrm{L}$ dye solution of desired concentration at $\mathrm{pH} 6.0$ and at temperatures $\left(30,40,50,60 \pm 0.5{ }^{\circ} \mathrm{C}\right)$ in a mechanical shaker $(120 \mathrm{rpm})$. After the defined time intervals, samples were withdrawn from the shaker, centrifuged and the supernatant solution was analyzed for residual dye concentration using a UV-Visible spectrophotometer. Effect of adsorbent dosage was studied by varying the carbon dose from 10 to $250 \mathrm{mg}$, taking $30 \mathrm{mg} / \mathrm{L}$ as initial dye concentration. For studies on the effect of $\mathrm{pH}$, the initial $30 \mathrm{mg} / \mathrm{L}$ dye solution was adjusted to a desired value using small amounts of dilute hydrochloric acid or sodium hydroxide and agitated with $25 \mathrm{mg}$ of the carbon. For temperature variation study $25 \mathrm{mg}$ of the carbon was agitated with $10,20,30,40,50$ and $60 \mathrm{mg} / \mathrm{L}$ of dye solution using a temperature controlled water bath-cum-shaker. Freundlich isotherm was derived from the studies on the effect of carbon dosage on the percent dye removal. Langmuir isotherm study was carried out with dye solutions of different initial concentrations ranging from 10, 20, 30, 40, 50 and $60 \mathrm{mg} / \mathrm{L}$ and agitating with a fixed carbon dose $(25 \mathrm{mg})$, until equilibrium was reached.

After adsorption of $30 \mathrm{mg} / \mathrm{L}$ of dye by $25 \mathrm{mg}$ of the carbon, the carbon loaded with dye was separated and gently washed with distilled water to remove any unadsorbed dye. The dye-laden carbons were agitated with $50 \mathrm{~mL}$ of neutral $\mathrm{pH}$ water, $0.1 \mathrm{M}$ sulphuric acid, hydrochloric acid, nitric acid, sodium chloride and sodium chloride with hydrochloric acid separately for $60 \mathrm{~min}$ to identify the regeneration process.

\section{Results and Discussion}

\section{Characterization of the adsorbent}

Activated carbons are a widely used adsorbent due to its high adsorption capacity, high surface area, micro porous structure and high degree of surface respectively. The wide 
usefulness of carbon is a result of their specific surface area, high chemical and mechanical stability. The chemical nature and pore structure usually determines the sorption activity. The physico chemical properties are listed in Table 1.

Table 1. Characteristics of the adsorbent.

\begin{tabular}{lc}
\hline \multicolumn{1}{c}{ Properties } & MOC \\
\hline Particle size, mm & 0.035 \\
Density, g/cc & 0.2785 \\
Moisture content, \% & 1.56 \\
Loss on ignition, \% & 92 \\
Acid insoluble matter & 1.58 \\
Water-soluble matter, \% & 0.52 \\
$\mathrm{pH}$ of aqueous solution & 6.90 \\
$\mathrm{pH}_{\mathrm{zpc}}$ & 6.72 \\
\hline
\end{tabular}

\section{Effect of carbon concentration}

The adsorption of the dyes on carbon was studied by varying the carbon concentration (10-250 $\mathrm{mg} / 50 \mathrm{~mL}$ ) for $30 \mathrm{mg} / \mathrm{L}$ of dye concentration. The percent adsorption increased with increase in the carbon concentration (Figure 1). This was attributed to increased carbon surface area and availability of more adsorption sites ${ }^{5,6}$. Hence the remaining parts of the experiments are carried out with the adsorbent dose of $25 \mathrm{mg} / 50 \mathrm{~mL}$.

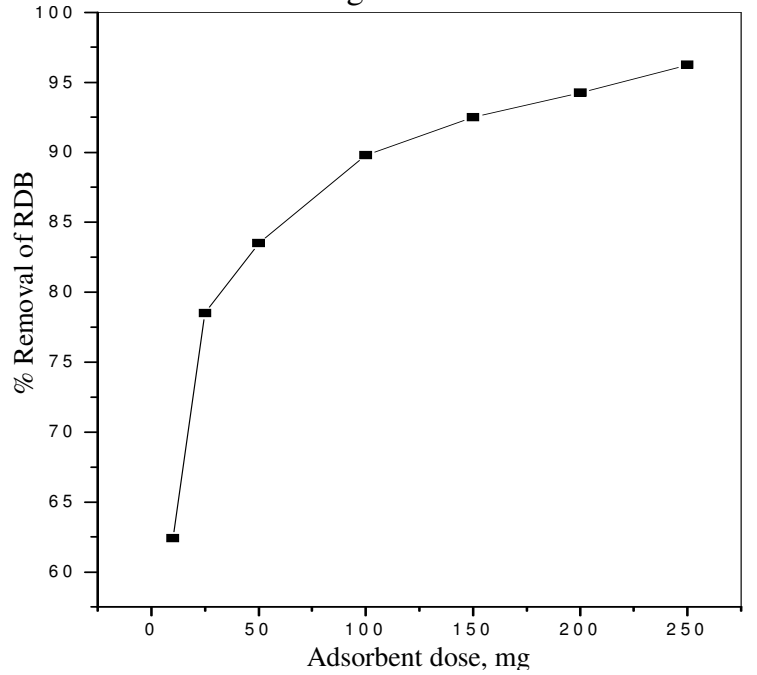

Figure 1. Effect of adsorbent dose on the removal of RDB dye.

$[\mathrm{RDB}]=30 \mathrm{mg} / \mathrm{L}$; Contact time $=60 \mathrm{~min} ; \mathrm{Temp}=30^{\circ} \mathrm{C}$

\section{Effect of contact time and initial dye concentration}

Effect of initial dye concentration on the rate of adsorption by Moringa oliefera bark carbon (chemically activated) was achieved as presented in Table 2. The amount of dye adsorbed at various intervals of time indicates that the removal of dye (adsorbate) initially increases with time but attains equilibrium within 40-60 minutes. The adsorption process was found to very rapid initially and a large fraction of the total concentration of dye was removed in the first 40 minutes. Though it was observed that adsorption of dye increased with an increase in dye concentration in the solution $^{5,6}$. But as a whole the percent removal decreases with the increase in dye concentration as observed in the Figure 2. 
Table 2. Equilibrium parameters for the adsorption of dye onto activated Carbon.

\begin{tabular}{|c|c|c|c|c|c|c|c|c|c|c|c|c|}
\hline \multirow[t]{2}{*}[\mathrm{RDB}]{$_{0}$} & \multicolumn{4}{|c|}{$\mathrm{C}_{\mathrm{e}}(\mathrm{mg} / \mathrm{L})$} & \multicolumn{4}{|c|}{$\mathrm{Q}_{\mathrm{e}}(\mathrm{mg} / \mathrm{g})$} & \multicolumn{4}{|c|}{ Dye removed (\%) } \\
\hline & $30^{\circ} \mathrm{C}$ & $40^{\circ} \mathrm{C}$ & $50^{\circ} \mathrm{C}$ & $60^{\circ} \mathrm{C}$ & $30^{\circ} \mathrm{C}$ & $40^{\circ} \mathrm{C}$ & $50^{\circ} \mathrm{C}$ & $60^{\circ} \mathrm{C}$ & $30^{\circ} \mathrm{C}$ & $40^{\circ} \mathrm{C}$ & $50^{\circ} \mathrm{C}$ & $60^{\circ} \mathrm{C}$ \\
\hline 10 & 1.3578 & 1.1358 & 0.9585 & 0.8012 & 17.2844 & 17.7284 & 18.0830 & 21.4569 & 86.4 & 88.6 & 90.4 & 92.0 \\
\hline 20 & 3.1725 & 2.8853 & 2.5489 & 2.2844 & 33.6550 & 34.2294 & 40.0125 & 40.4986 & 84.1 & 85.6 & 87.3 & 88.6 \\
\hline 30 & 5.4592 & 5.3142 & 5.0951 & 4.7527 & 49.0816 & 49.3716 & 58.1666 & 59.3523 & 81.8 & 82.3 & 83.0 & 84.2 \\
\hline 40 & 8.5885 & 8.1142 & 7.7546 & 7.3449 & 62.8230 & 63.7716 & 68.5454 & 70.6289 & 78.5 & 79.7 & 80.6 & 81.6 \\
\hline 50 & 13.4998 & 13.1757 & 12.8092 & 12.5715 & 73.0004 & 73.6486 & 73.8473 & 76.3646 & 73.0 & 73.6 & 74.4 & 74.9 \\
\hline 60 & 18.9546 & 18.6493 & 18.2947 & 17.7888 & 82.0908 & 82.7014 & 83.4106 & 84.4224 & 68.4 & 68.9 & 69.5 & 70.4 \\
\hline
\end{tabular}

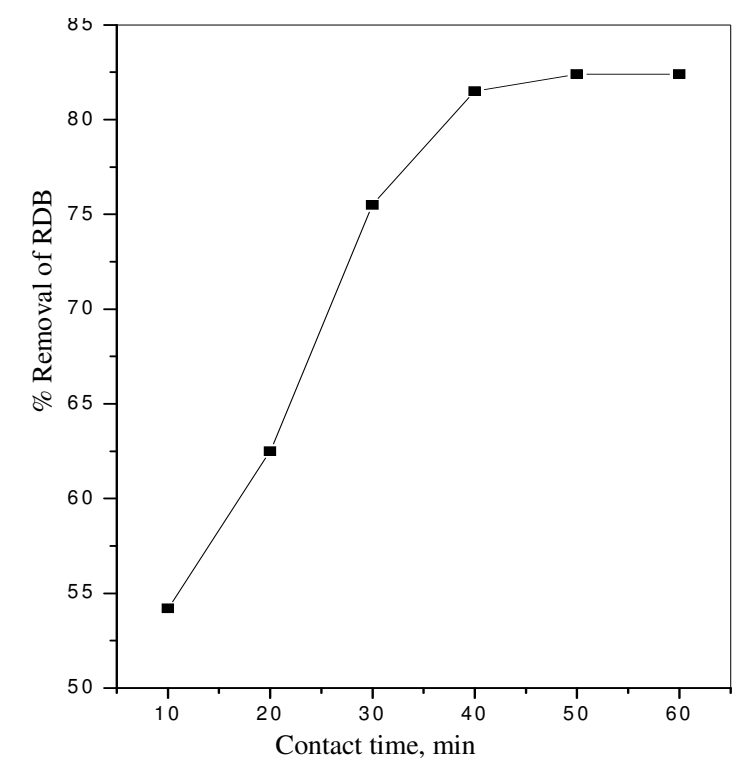

Figure 2. Effect of contact time on the removal of RDB by MOC.

[RDB] $=30 \mathrm{mg} / \mathrm{L}$; Adsorbent dose $=25 \mathrm{mg} / 50 \mathrm{~mL}$ 
For a particular experiment, the rate of adsorption decreased with time, it gradually approached a maximum adsorption and owing to continuous decrease in the concentration driving force and it also indicate that the adsorbent is saturated at this level. In addition, it is observed that initial rate of adsorption was greater for higher initial dye concentration because as the resistance to the dye uptake decreased, the mass transfer driving force increased. The time variation adsorption increases continuously and seems to smooth which, is indicative of the formation of monolayer coverage on the surface of adsorbent ${ }^{5,6}$.

\section{Adsorption isotherm}

In order to quantify the adsorption capacity of the Moringa oliefera bark carbon for removal of rhodamine B, the experimental data corresponding to the isotherms were fitted according to Langmuir ${ }^{7}$ and the Freundlich ${ }^{8}$ equations. These equilibrium isotherms were expressed by plotting the amount of dye held by the Moringa oliefera bark carbon versus the equilibrium concentration of Rhodamine B left in solution

$$
\mathrm{C}_{\mathrm{e}} / \mathrm{Q}_{\mathrm{e}}=1 / \mathrm{Q}_{\mathrm{m}} \mathrm{b}+\mathrm{C}_{\mathrm{e}} / \mathrm{Q}_{\mathrm{m}}
$$

Where $C_{e}$ is the equilibrium concentration $(\mathrm{mg} / \mathrm{L}), Q_{e}$ is the amount adsorbed at equilibrium $\left(\mathrm{mg} / \mathrm{g}\right.$ ) and $\mathrm{Q}_{\mathrm{m}}$ and $\mathrm{b}$ is Langmuir constants related to adsorption efficiency and energy of adsorption, respectively. The linear plots of $\mathrm{C}_{\mathrm{e}} \mathrm{Q}_{\mathrm{e}}$ versus $\mathrm{C}_{\mathrm{e}}$ suggest the applicability of the Langmuir isotherms (Figure 3). The values of $\mathrm{Q}_{\mathrm{m}}$ and $\mathrm{b}$ were determined from slope and intercepts of the plots and are presented in Table 3. From the results, it is clear that the value of adsorption energy $b$ of the carbon increases on increasing the temperature. The values of $Q_{m}$ and $\mathrm{b}$ conclude that the maximum adsorption corresponds to a saturated monolayer of adsorbate molecules on adsorbent surface with constant energy and no transmission of adsorbate in the plane of the adsorbent surface. The observed $b$ value confirms the endothermic nature of the process involved in the system ${ }^{9-11}$. To confirm the favorability of the adsorption process, the separation factor $\left(\mathrm{R}_{\mathrm{L}}\right)$ was calculated and presented in Table 4 . The values were found to be between 0 and 1 and confirm that the ongoing adsorption process is favorable ${ }^{12}$.

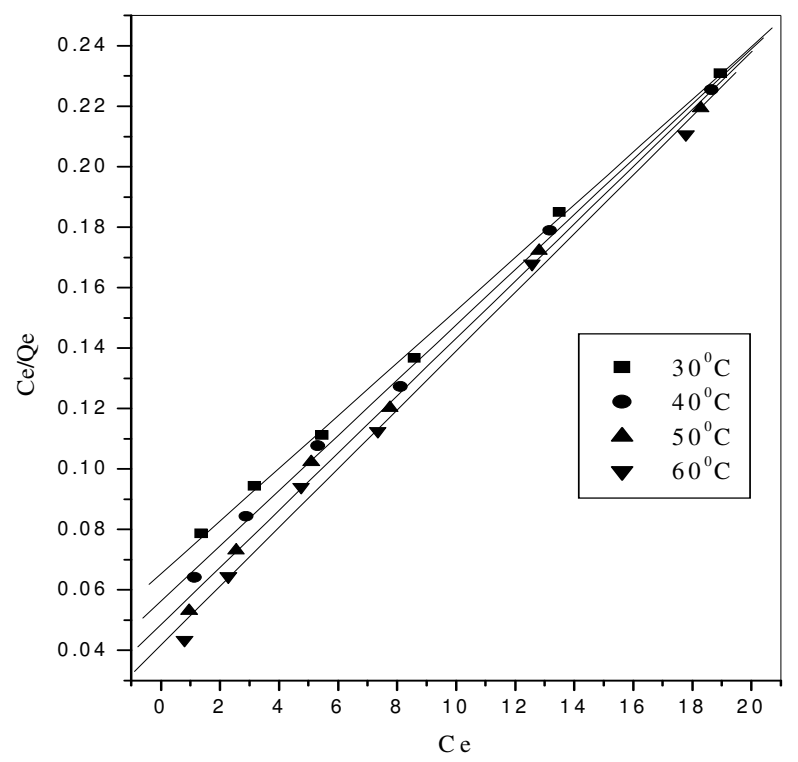

Figure 3. Langmuir isotherm for the adsorption of RDB onto MOC. 
Table 3. Langmuir isotherm results.

\begin{tabular}{ccccc}
\hline \multirow{2}{*}{ Dye } & $\begin{array}{c}\text { Temp } \\
{ }^{0} \mathrm{C}\end{array}$ & \multicolumn{3}{c}{ Statistical parameters/constants } \\
\cline { 3 - 5 } & 30 & 0.9981 & 114.68 & 0.1300 \\
& 40 & 0.9992 & 109.41 & 0.1600 \\
RDB & 40 & $\mathrm{Q}_{\mathrm{m}}$ & $\mathrm{b}$ \\
& 50 & 0.9983 & 105.60 & 0.2000 \\
& 60 & 0.9998 & 102.80 & 0.2300 \\
\hline
\end{tabular}

Table 4. Dimensionless separation factor $\left(\mathrm{R}_{\mathrm{L}}\right)$.

\begin{tabular}{ccccc}
\hline$[\mathrm{RDB}]_{0}$ & \multicolumn{4}{c}{ Temperature, ${ }^{0} \mathrm{C}$} \\
\cline { 2 - 5 } $\mathrm{mg} / \mathrm{L}$ & 30 & 40 & 50 & 60 \\
\hline 10 & 0.43 & 0.38 & 0.33 & 0.30 \\
20 & 0.28 & 0.24 & 0.20 & 0.18 \\
30 & 0.20 & 0.17 & 0.14 & 0.13 \\
40 & 0.16 & 0.14 & 0.11 & 0.10 \\
50 & 0.13 & 0.11 & 0.09 & 0.08 \\
60 & 0.11 & 0.09 & 0.08 & 0.07 \\
\hline
\end{tabular}

The Freundlich equation was employed for the adsorption of rhodamine B dye on the adsorbent. The Freundlich isotherm was represented by

$$
\log \mathrm{Q}_{\mathrm{e}}=\log \mathrm{K}_{\mathrm{f}}+1 / \mathrm{n} \log \mathrm{C}_{\mathrm{e}}
$$

Where $\mathrm{Q}_{\mathrm{e}}$ is the amount of rhodamine $\mathrm{B}$ dye adsorbed $(\mathrm{mg} / \mathrm{g}), \mathrm{C}_{\mathrm{e}}$ is the equilibrium concentration of dye in solution $(\mathrm{mg} / \mathrm{L})$ and $\mathrm{K}_{\mathrm{f}}$ and $\mathrm{n}$ are constants incorporating the factors affecting the adsorption capacity and intensity of adsorption, respectively. Linear plots of $\log \mathrm{Q}_{\mathrm{e}}$ versus $\log \mathrm{C}_{\mathrm{e}}$ shows that the adsorption of rhodamine $\mathrm{B}$ dye obey the Freundlich adsorption isotherm (Figure.4). The values of $\mathrm{K}_{\mathrm{f}}$ and $\mathrm{n}$ given in the Table 5 show that the increase in negative charges on the adsorbent surface that makes electrostatic force like Van der Waal's between the carbon surface and dye ion. The molecular weight, size and radii either limit or increase the possibility of the adsorption of the dye onto adsorbent. However, the values clearly show the dominance in adsorption capacity. The intensity of adsorption is an indicative of the bond energies between dye and adsorbent and the possibility of slight chemisorptions rather than physisorption ${ }^{10,11}$. However, the multilayer adsorption of RDB through the percolation process may be possible. The values of $n$ are greater than one indicating the adsorption is much more favorable ${ }^{12}$.

Table 5. Freundlich isotherm results

\begin{tabular}{ccccc}
\hline Dye & $\begin{array}{c}\text { Temp } \\
{ }^{0} \mathrm{C}\end{array}$ & \multicolumn{3}{c}{ Statistical parameters/constants } \\
\cline { 3 - 5 } & 30 & 0.9978 & 0.1900 & 1.6900 \\
& 30 & $\mathrm{~K}_{\mathrm{f}}$ & $\mathrm{n}$ \\
$\mathrm{*}$ RDB & 40 & 0.9989 & 0.2300 & 1.8000 \\
& 50 & 0.9998 & 0.2700 & 1.9200 \\
& 60 & 0.9904 & 0.3000 & 2.0300 \\
\hline
\end{tabular}




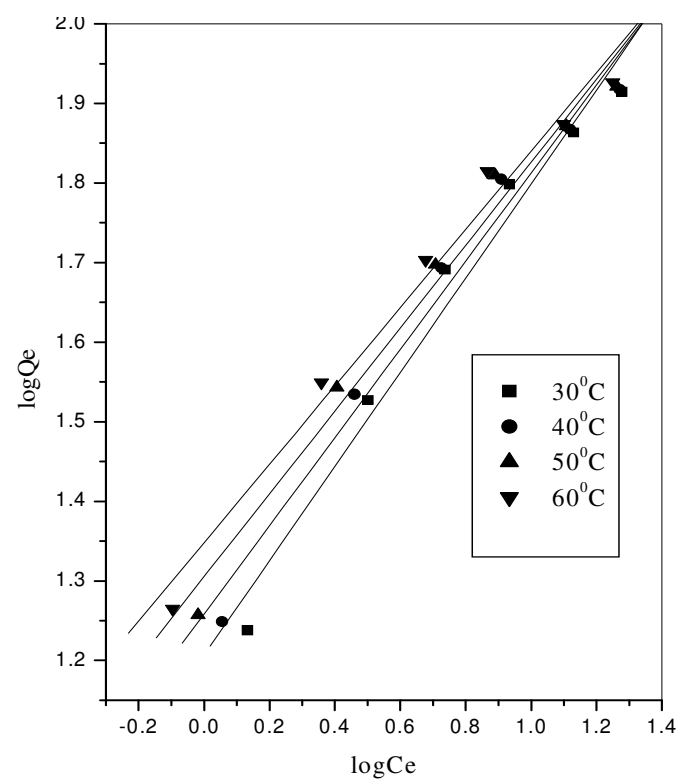

Figure 4. Linear Freundlich isotherm for the adsorption of RDB by MOC.

\section{Effect of temperature}

The adsorption capacity of the carbon increased with increase in the temperature of the system from $30^{\circ}-60^{\circ} \mathrm{C}$. Thermodynamic parameters such as change in free energy were determined using the following equations $\left(\Delta \mathrm{G}^{\circ}\right)(\mathrm{kJ} / \mathrm{mol})$, enthalpy $\left(\Delta \mathrm{H}^{\circ}\right)(\mathrm{kJ} / \mathrm{mol})$ and entropy $\left(\Delta \mathrm{S}^{\circ}\right)(\mathrm{J} / \mathrm{Kmol})$ were determined using the following equations.

$$
\begin{aligned}
\mathrm{K}_{0} & =\mathrm{C}_{\text {solid }} / \mathrm{C}_{\text {liquid }} \\
\Delta \mathrm{G}^{\circ} & =-\mathrm{RT} \ln \mathrm{K}_{\mathrm{O}} \\
\log \mathrm{K}_{0} & =\Delta \mathrm{S}^{\circ} /(2.303 \mathrm{RT})-\Delta \mathrm{H}^{\circ} /(2.303 \mathrm{RT})
\end{aligned}
$$

Where, $\mathrm{K}_{\mathrm{o}}$ is the equilibrium constant, $\mathrm{C}_{\text {solid }}$ is the solid phase concentration at equilibrium ( $\mathrm{mg} / \mathrm{L}$ ), $\mathrm{C}_{\text {liquid }}$ is the liquid phase concentration at equilibrium ( $\mathrm{mg} / \mathrm{L}$ ), $\mathrm{T}$ is the temperature in Kelvin and $\mathrm{R}$ is the gas constant. The $\Delta \mathrm{H}^{\circ}$ and $\Delta \mathrm{S}^{\circ}$ values obtained from the slope and intercept of van't Hoff plots have presented in Table 6 . The values $\Delta \mathrm{H}^{\circ}$ is with in the range of 1 to $93 \mathrm{~kJ} / \mathrm{mol}$ indicates the physisorption. From the results we could make out that physisorption is much more favorable for the adsorption of RDB. The positive values of $\Delta \mathrm{H}^{\circ}$ show the endothermic nature of adsorption and it governs the possibility of physical adsorption ${ }^{11,13}$. Because in the case of physical adsorption, while increasing the temperature of the system, the extent of dye adsorption increases, this rules out the possibility of chemisorption $^{13}$. The low $\Delta \mathrm{H}^{\circ}$ value depicts dye is physisorbed onto adsorbent.

The negative values of $\Delta \mathrm{G}^{\circ}$ (Table 6) shows the adsorption is highly favorable and spontaneous. The positive values of $\Delta \mathrm{S}^{\circ}$ (Table 6) shows the increased disorder and randomness at the solid solution interface of RDB with MOC adsorbent, while the adsorption there are some structural changes in the dye and the adsorbent occur. The adsorbed water molecules, which have displaced by the adsorbate species, gain more translational entropy than is lost by the adsorbate molecules, thus allowing the prevalence of randomness in the system. The enhancement of adsorption capacity of the activated carbon at higher temperatures was attributed to the enlargement of pore size and activation of the adsorbent surface ${ }^{12-14}$. 
Table 6. Equilibrium constant and thermodynamic parameters for the adsorption of dye onto carbon.

\begin{tabular}{|c|c|c|c|c|c|c|c|c|c|c|}
\hline \multirow[b]{2}{*}[\mathrm{D}]{$_{0}$} & \multicolumn{4}{|c|}{$\mathrm{K}_{0}$} & \multicolumn{4}{|c|}{$\Delta \mathrm{G}^{\mathrm{o}}$} & \multirow[b]{2}{*}{$\Delta \mathrm{H}^{\mathrm{o}}$} & \multirow[b]{2}{*}{$\Delta S^{\mathrm{o}}$} \\
\hline & $30^{\circ} \mathrm{C}$ & $40^{\circ} \mathrm{C}$ & $50^{\circ} \mathrm{C}$ & $60 \mathrm{C}^{\mathrm{o}}$ & $30^{\circ} \mathrm{C}$ & $40^{\circ} \mathrm{C}$ & $50^{\circ} \mathrm{C}$ & $60^{\circ} \mathrm{C}$ & & \\
\hline 10 & 6.36 & 7.80 & 9.43 & 11.48 & -4.66 & -5.34 & -6.02 & -6.75 & 16.26 & 68.92 \\
\hline 20 & 5.30 & 5.93 & 6.85 & 7.76 & -4.20 & -4.63 & -5.16 & -5.67 & 10.63 & 48.86 \\
\hline 30 & 4.50 & 4.65 & 4.89 & 5.31 & -3.78 & -3.99 & -4.26 & -4.62 & 5.33 & 28.38 \\
\hline 40 & 3.66 & 3.93 & 4.16 & 4.45 & -3.26 & -3.56 & -3.82 & -4.13 & 4.54 & 27.35 \\
\hline 50 & 2.70 & 2.79 & 2.90 & 2.98 & -2.50 & -2.67 & -2.86 & -3.02 & 27.22 & 17.24 \\
\hline 60 & 2.17 & 2.22 & 2.28 & 2.37 & -1.94 & -2.07 & -2.21 & -2.39 & 24.61 & 14.61 \\
\hline
\end{tabular}

Kinetics of adsorption

In the present study, the kinetics of the dye removal was carried out to understand the behaviour of these low cost carbon adsorbents. The adsorption of dye from an aqueous follows reversible first order kinetics, when a single species are considered on a heterogeneous surface. The heterogeneous equilibrium between the dye solutions and the activated carbon are expressed as:

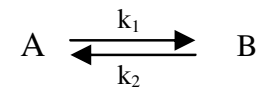

Where, $\mathrm{k}_{1}$ is the forward rate constant and $\mathrm{k}_{2}$ is the backward rate constant. A represents dye remaining in the aqueous solution and $\mathrm{B}$ represent dye adsorbed on the surface of activated carbon. The equilibrium constant $\left(\mathrm{K}_{0}\right)$ is the ration of the concentration adsorbate in adsorbent and in aqueous solution $\left(\mathrm{K}_{0}=\mathrm{k}_{1} / \mathrm{k}_{2}\right)$.

In order to study the kinetics of the adsorption process under consideration the following kinetic equation proposed by Natarajan and Khalaf as cited in literature has been employed ${ }^{1}$.

$$
\log \mathrm{C}_{0} / \mathrm{C}_{\mathrm{t}}=\left(\mathrm{K}_{\mathrm{ad}} / 2.303\right) \mathrm{t}
$$

Where, $\mathrm{C}_{0}$ and $\mathrm{C}_{\mathrm{t}}$ denotes the concentration of the adsorbate at zero and time respectively. The rate constants $\left(\mathrm{K}_{\mathrm{ad}}\right)$ for the adsorption processes have been calculated from the slope of the linear plots of $\log \mathrm{C}_{0} / \mathrm{C}_{\mathrm{t}}$ versus $\mathrm{t}$ for different concentrations and temperatures. The determination of rate constants as described in literature given by

$$
\mathrm{K}_{\mathrm{ad}}=\mathrm{k}_{1}+\mathrm{k}_{2}=\mathrm{k} 1+\left(\mathrm{k}_{1} / \mathrm{K}_{0}\right)=\mathrm{k}_{1}\left[1+1 / \mathrm{K}_{0}\right]
$$

The overall rate constant $\mathrm{k}_{\mathrm{ad}}$ for the adsorption of dye at different temperatures are calculated from the slopes of the linear Natarajan-Khalaf plots. The rate constant values are collected in Table 7 shows that the rate constant $\left(\mathrm{k}_{\mathrm{ad}}\right)$ increases with increase in temperature suggesting that the adsorption process in endothermic in nature. Further, $\mathrm{k}_{\mathrm{ad}}$ values decrease with increase in initial concentration of the dye. In cases of strict surface adsorption a variation of rate should be proportional to the first power of concentration. However, when pore diffusion limits the adsorption process, the relationship between initial dye concentration and rate of reaction will not be linear. Thus, in the present study pore diffusion limits the overall rate of dye adsorption. The over all rate of adsorption is separated into the rate of forward and reverse reactions using the above equation. The rate constants for the forward and reverse processes are also collected in Table 7 indicate that, at all initial concentrations and temperatures, the forward rate constant is much higher than the reverse rate constant suggesting that the rate of adsorption is clearly dominant ${ }^{1,11,13}$. 
Table 7. Rate constants for the adsorption of RDB dye $\left(10^{3} \mathrm{k}_{\mathrm{ad}}\right.$, $\left.\mathrm{min}^{-1}\right)$ and the constants for forward $\left(10^{3} \mathrm{k}_{1}, \mathrm{~min}^{-1}\right)$ and reverse $\left(10^{3} \mathrm{k}_{2}, \mathrm{~min}^{-1}\right)$ process.

\begin{tabular}{cccccccccccccc}
\hline & \multicolumn{10}{c}{ Temperature, ${ }^{0} \mathrm{C}$} \\
\cline { 2 - 14 }$]_{0}$ & \multicolumn{10}{c}{$\mathrm{k}_{\mathrm{ad}}$} & \multicolumn{10}{c}{30} & \multicolumn{1}{c}{40} & \multicolumn{3}{c}{50} & \multicolumn{3}{c}{60} \\
\hline \multicolumn{1}{c}{$30^{\circ}$} & $40^{\circ}$ & $50^{\circ}$ & $60^{\circ}$ & $\mathrm{k}_{1}$ & $\mathrm{k}_{2}$ & $\mathrm{k}_{1}$ & $\mathrm{k}_{2}$ & $\mathrm{k}_{1}$ & $\mathrm{k}_{2}$ & $\mathrm{k}_{1}$ & $\mathrm{k}_{2}$ \\
\hline 10 & 12.39 & 12.27 & 14.62 & 15.02 & 10.71 & 1.68 & 10.88 & 1.39 & 13.22 & 1.40 & 13.82 & 1.20 \\
20 & 11.24 & 13.27 & 12.64 & 13.43 & 9.46 & 1.78 & 11.36 & 1.91 & 11.03 & 1.61 & 13.90 & 1.53 \\
30 & 9.56 & 9.88 & 9.86 & 10.73 & 7.82 & 1.74 & 8.13 & 1.75 & 8.19 & 1.67 & 9.03 & 1.70 \\
40 & 8.13 & 8.77 & 8.98 & 9.47 & 6.38 & 1.75 & 6.99 & 1.78 & 7.24 & 1.74 & 7.73 & 1.74 \\
50 & 6.72 & 7.53 & 7.37 & 7.09 & 4.91 & 1.81 & 5.55 & 1.98 & 5.48 & 1.89 & 5.29 & 1.78 \\
60 & 5.83 & 5.94 & 5.92 & 6.10 & 3.99 & 1.84 & 4.09 & 1.85 & 4.11 & 1.81 & 4.29 & 1.81 \\
\hline
\end{tabular}

Intraparticle diffusion

The most commonly used technique for identifying the mechanism involved in the sorption process is by fitting the experimental data in an intraparticle diffusion plot. Previous studies by various researchers ${ }^{1-5}$ showed that the plot of $\mathrm{Q}$ versus $\mathrm{t}^{0.5}$ represents multi linearity, which characterizes the two or more steps involved in the sorption process. According to Weber and Morris, an intraparticle diffusion coefficient $\mathrm{K}_{\mathrm{p}}$ is defined by the equation:

$$
\mathrm{K}_{\mathrm{p}}=\mathrm{Q} / \mathrm{t}^{0.5}+\mathrm{C}
$$

Thus the $\mathrm{K}_{\mathrm{p}}\left(\mathrm{mg} / \mathrm{g} \min ^{0.5}\right)$ value can be obtained from the slope of the plot of $\mathrm{Q}_{\mathrm{t}}(\mathrm{mg} / \mathrm{g})$ versus $\mathrm{t}^{0.5}$ for rhodamine $\mathrm{B}$. shows that the sorption process tends to be followed by two phases. The two phases in the intra-particle diffusion plot suggest that the sorption process proceeds by surface sorption and intra-particle diffusion ${ }^{15,16}$. The initial curved portion of the plot indicates a boundary layer effect while the second linear portion is due to intra-particle or pore diffusion. The slope of the second linear portion of the plot has been defined as the intraparticle diffusion parameter $\mathrm{K}_{\mathrm{p}}\left(\mathrm{mg} / \mathrm{g} \min ^{0.5}\right)$. On the other hand, the intercept of the plot reflects the boundary layer effect. The higher intercept value shows the greater contribution of the surface sorption in the rate limiting step. The calculated intra-particle diffusion coefficient $\mathrm{K}_{\mathrm{p}}$ value was given by 0.235 , $0.295,0.342,0.385,0.425$ and $0.492 \mathrm{mg} / \mathrm{g} \mathrm{min}^{0.5}$ for initial dye concentration of 10,20 , $30,40,50$ and $60 \mathrm{mg} / \mathrm{L}$ at $30^{\circ} \mathrm{C}$.

\section{Effect of $p H$}

$\mathrm{PH}$ is one of the most important parameters controlling the adsorption process. The effect of $\mathrm{pH}$ of the solution on the adsorption of RDB ions on MOC was determined. The result is shown in Figure. 5. The $\mathrm{pH}$ of the solution was controlled by the addition of $\mathrm{HCl}$ or $\mathrm{NaOH}$. The maximum in uptake of RDB was obtained at $\mathrm{pH}$ 3.0-6.5. However, when the $\mathrm{pH}$ of the solution was increased (more than $\mathrm{pH}$ 9), the uptake of RDB ions was increased. It appears that a change in $\mathrm{pH}$ of the solution results in the formation of different ionic species, and different carbon surface charge. At $\mathrm{pH}$ values lower than 6.5, the RDB ions can enter into the pore structure. At a $\mathrm{pH}$ value higher than 6.5 , the zwitterions form of RDB in water may increase the aggregation of RDB to form a bigger molecular form (dimer) and become unable to enter into the pore structure of the carbon surface. The greater aggregation of the zwitterionic form is due to the attractive electrostatic interaction between the carboxyl and xanthane groups of the monomer. 
At a pH value higher than 9, the existence of $\mathrm{OH}^{-}$creates a competition between $-\mathrm{N}^{+}$ and $\mathrm{COO}^{-}$and it will decrease the aggregation of $\mathrm{RDB}$, which causes an increase in the adsorption of RDB ions on the carbon surface. The effect electrostatic force of attraction and repulsion between the carbon surface and the RDB ions cannot explain the result ${ }^{12,17}$.

Effect of the ionic strength on the adsorption of $R D B$

The effect of sodium chloride on the adsorption of RDB on MOC is shown in Figure 6. In a low solution concentration $\mathrm{NaCl}$ had little influence on the adsorption capacity. At higher ionic strength the adsorption RDB will be increased due to the partial neutralization of the positive charge on the carbon surface and a consequent compression of the electrical double layer by the $\mathrm{Cl}^{-}$anion. The chloride ion can also enhances adsorption of RDB ion onto MOC by pairing of their charges and hence reducing the repulsion between the RDB molecules adsorbed on the surface. This initiates carbon to adsorb more of positive RDB ions ${ }^{1,17}$

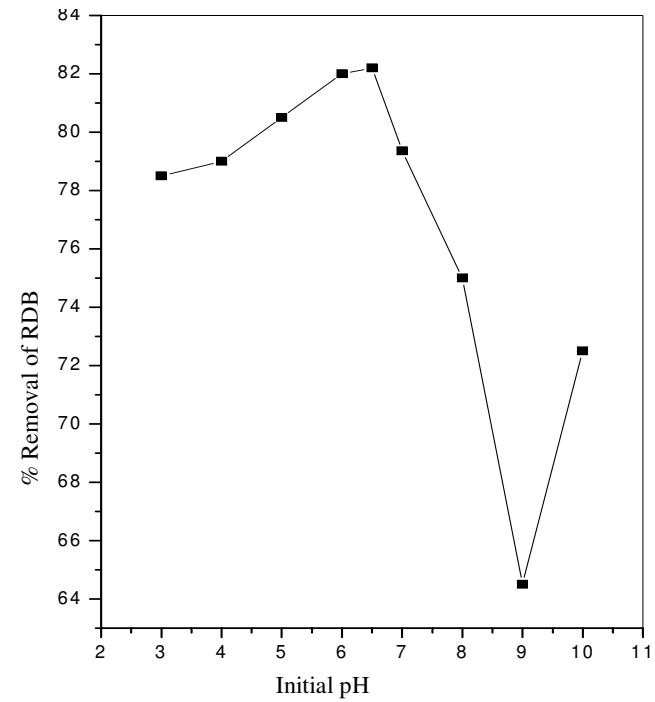

Figure 5. Effect of $\mathrm{pH}$ on the removal of RDB by MOC.

$[\mathrm{RDB}]=30 \mathrm{mg} / \mathrm{L} ;$ Contact time $=60 \mathrm{~min}$; Adsorbent dose $=25 \mathrm{mg} / 50 \mathrm{~mL}$

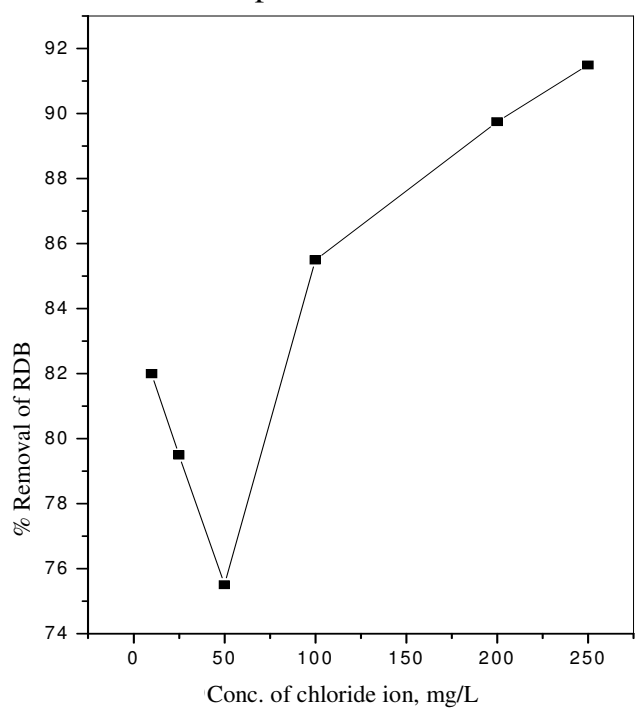

Figure 6. Effect of chloride ion on the removal of RDB by MOC.

$[\mathrm{RDB}]=30 \mathrm{mg} / \mathrm{L} ; \mathrm{pH}=7$; Contact time $=60 \mathrm{~min}$; Adsorbent dose $=25 \mathrm{mg} / 50 \mathrm{~mL}$

\section{Desorption studies}

Desorption studies help to elucidate the nature of adsorption and recycling of the spent adsorbent and the dye. The effect of various reagents used for desorption studies indicate that hydrochloric acid is a better reagent for desorption, because more than $71 \%$ adsorbed dye were removed. The reversibility of adsorbed dye in mineral acid is in agreement with the $\mathrm{pH}$ dependent results obtained. The desorption of dye by mineral acids indicates that the dyes were adsorbed onto the activated carbon through by physisorption mechanisms ${ }^{12,18}$.

\section{Conclusions}

The experimental data were very well correlated by the Langmuir and Freundlich adsorption isotherms and the isotherm parameters were calculated. The low as well high $\mathrm{pH}$ value shows the optimum amount of adsorption of the dye. The amount of rhodamine B adsorbed increased with increasing ionic strength and increased with increase in temperature. 
The dimensionless separation factor $\left(\mathrm{R}_{\mathrm{L}}\right)$ showed that the activated carbon could be used for the removal of rhodamine $\mathrm{B}$ from aqueous solution. The values of $\Delta \mathrm{H}^{\circ}, \Delta \mathrm{S}^{\circ}$ and $\Delta \mathrm{G}^{\circ}$ results shows that the carbon employed has a considerable potential as an adsorbent for the removal of rhodamine B.

\section{Acknowledgement}

The authors acknowledge sincere thanks to Mrs. Mala Arivoli, The Principal, H H The Rajah's Government College, Pudukkottai and The Director of Collegiate Education, Chennai for carrying out this research work successfully.

\section{References}

1. Arivoli S, Kinetic and thermodynamic studies on the adsorption of some metal ions and dyes onto low cost activated carbons, Ph D., Thesis, Gandhigram Rural University, Gandhigram, India, 2007.

2. Sekaran G, Shanmugasundaram K A, Mariappan M and Raghavan K V, Indian J Chem Technol., 1995, 2, 311.

3. Selvarani K, Studies on Low cost Adsorbents for the removal of organic and Inorganics from Water, $\mathrm{Ph}$ D., Thesis, Regional Engineering College, Thiruchirapalli, India, 2000.

4. Jia Y F and Thomas K K, Langmuir, 2002, 18, 470-478.

5. Namasivayam C, Muniasamy N, Gayathri K, Rani M and Renganathan K, Biores Technol., 1996, 57, 37.

6. Namasivayam C and Yamuna R T, Environ Pollut., 1995, 89, 1.

7. Langmuir I, J Am Chem Soc., 1918, 40, 1361.

8. Freundlich H, Z Phys Chemie, 1906, 57, 384.

9. Krishna D G and Bhattacharyya G, Appl Clay Sci, 2002, 20, 295.

10. Arivoli S, Viji Jain M and Rajachandrasekar T, Mat Sci Res India, 2006, 3, 241-250.

11. Arivoli S and Hema M, Int J Phys Sci., 2007, 2, 10-17.

12. Arivoli S, Venkatraman B R, Rajachandrasekar T and Hema M, Res J Chem Environ., 2007, 17, 70-78.

13. Arivoli S, Kalpana K, Sudha R and Rajachandrasekar T, E Journal Chemistry, 2007, 4, 238-254.

14. Renmin Gong, Yingzhi Sun, Jian Chen, Huijun Liu, Chao yang, Dyes and Pigments, 2005, 67, 179.

15. Vadivelan V and Vasanthkumar K, J Colloid Interf Sci., 2005, 286, 91.

16. Weber W J, Principle and Application of Water Chemistry, Edited by Faust S D and Hunter J V, Wiley, New York, 1967.

17. Yupeng Guo, Jingzhu Zhao, Hui Zhang, Shaofeng Yang, Zichen Wang and Hongding $\mathrm{Xu}$, Dyes and Pigments, 2005, 66, 123-128.

18. Sreedhar M K and Anirudhan T S, Indian J Environ Protect., 1999, 19, 8. 


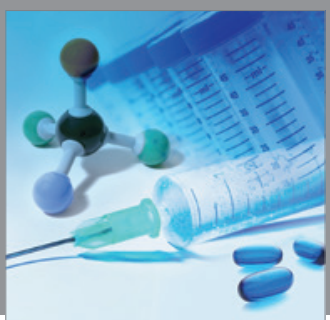

International Journal of

Medicinal Chemistry

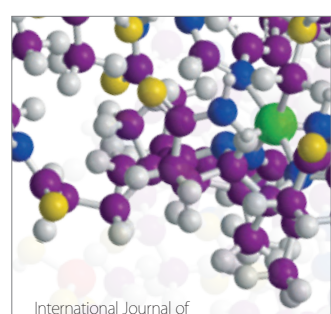

Carbohydrate Chemistry

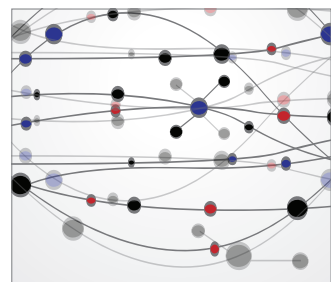

The Scientific World Journal
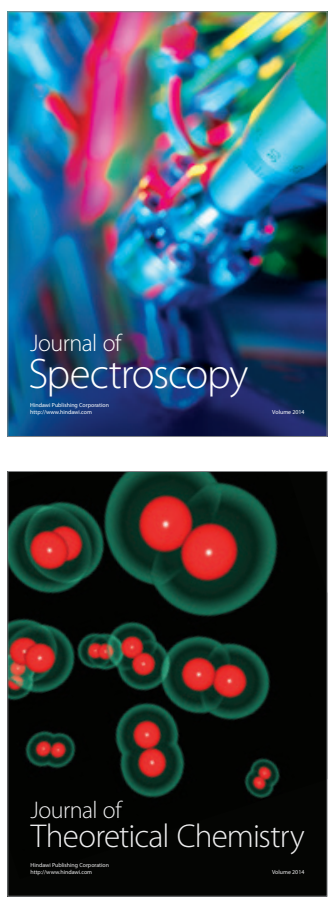
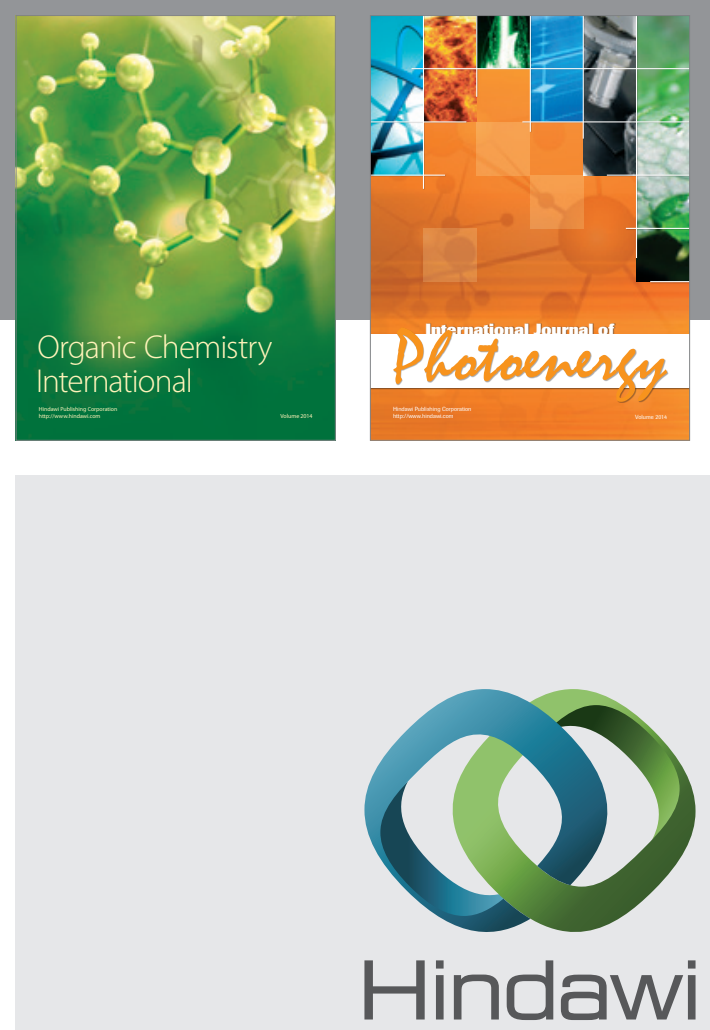

Submit your manuscripts at

http://www.hindawi.com
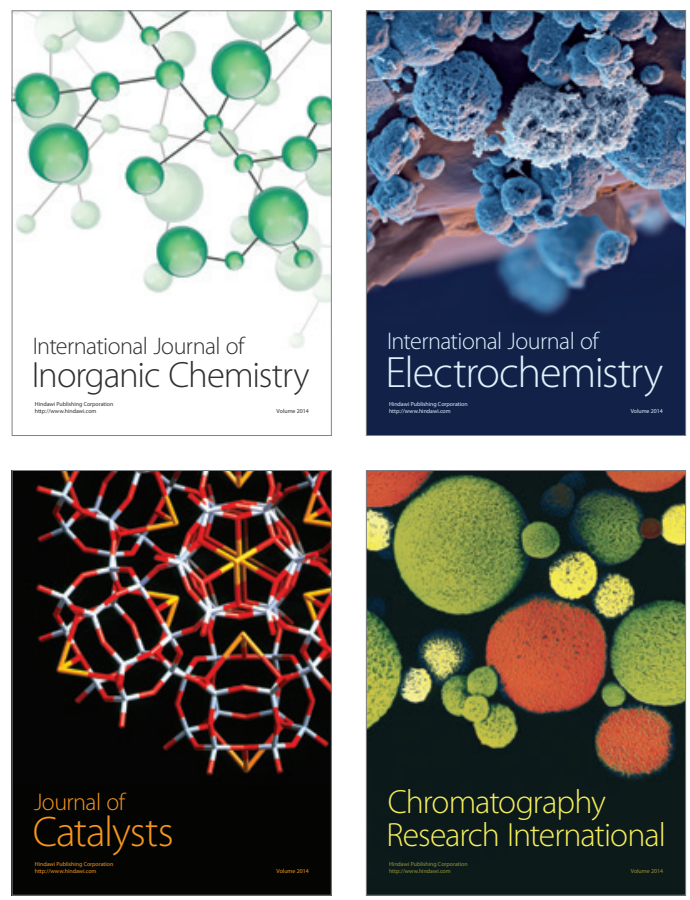
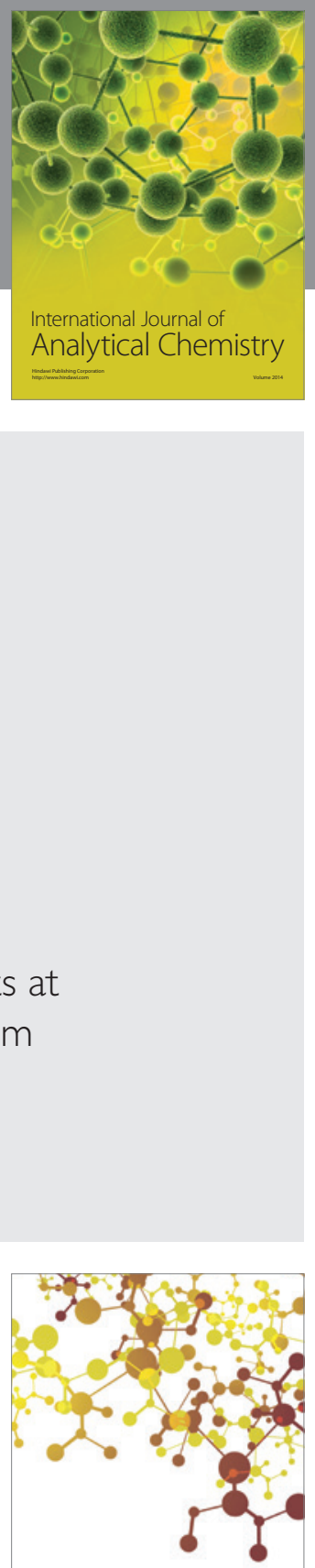

Journal of

Applied Chemistry
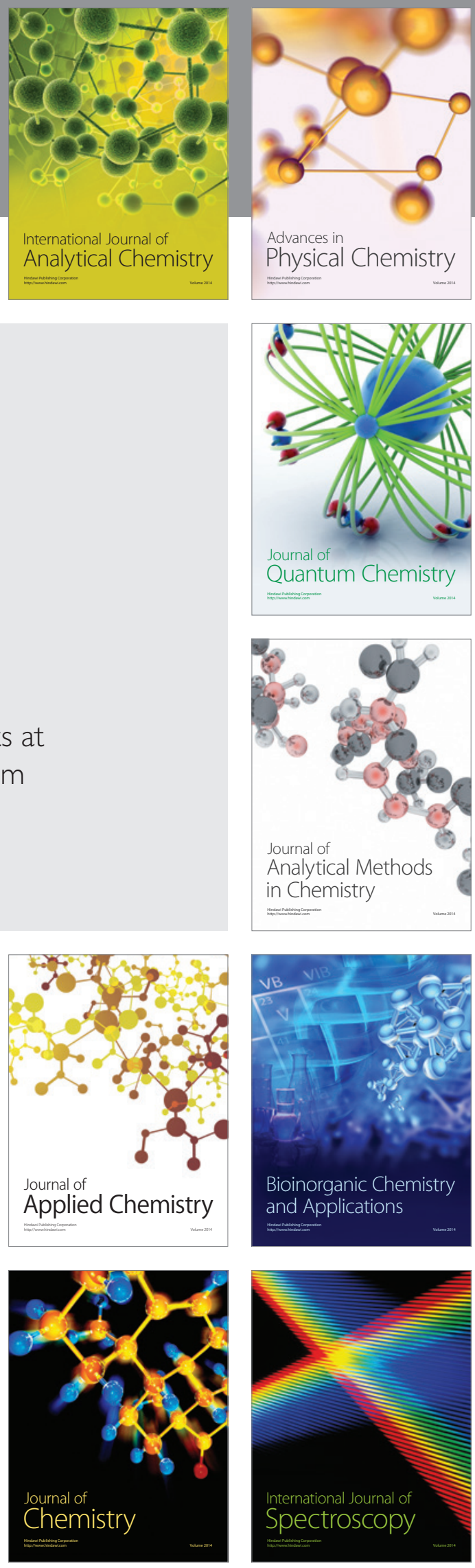